\title{
DETERMINATION OF TERNARY MIXTURES OF DEXTROMETHORPHAN HYDROBROMIDE, PSEUDOEPHEDRINE HYDROCHLORIDE AND TRIPROLIDINE HYDROCHLORIDE IN SYRUPS BY PARTIAL LEAST-SQUARES MULTIVARIATE CALIBRATION
}

\author{
Özlem Aksu Dönmez”, Abdürrezzak Bozdogan and Gönül Kunt \\ Yildiz Technical University, Department of Chemistry 34210, \\ Davutpasa, Istanbul, Turkey
}

\begin{abstract}
PLS-2, a partial least-squares multivariate calibration, was used for the determination of dextromethorphan hydrobromide (DEX), pseudoephedrine hydrochloride (PSE) and triprolidine hydrochloride (TRP) in syrup samples. The method allows the simultaneous quantification of the analytes that the closely overlapping spectral bands are not efficiently solved. The calibration set consisting of 27 samples with $60,80,100 \mu \mathrm{g} \mathrm{mL}^{-1}$ of DEX, 180, 240, 300 $\mu \mathrm{g} \mathrm{mL}^{-1}$ of PSE and $8,10,12 \mu \mathrm{g} \mathrm{mL}^{-1}$ of TRP was used for calibration matrix. The absorbances were recorded between 230 and $320 \mathrm{~nm}$ every $5 \mathrm{~nm}$. The accuracy and precision of the method have been determined and the method has been validated by synthetic mixtures.
\end{abstract}

Keywords: Dextromethorphan hydrobromide, pseudoephedrine hydrochloride, triprolidine hydrochloride, multivariate calibration.

\section{INTRODUCTION}

The combination of TRP with PSE and DEX is used to relieve the symptoms of colds and flu, such as nasal congestion, cough and runny nose,

- Corresponding author: Özlem Aksu Dönmez

Tel: +90 2124491950 ; Fax: +902124491514

E-mail: oziaksu@yahoo.com; oaksu@yildiz.edu.tr 
where these are associated with a dry cough.

The simultaneous analysis of these components has been performed by a few methods, including UV spectrophotometry /1,2/ and HPLC /3/. In spite of widespread use of HPLC and other conventionel spectrophotometric methods, these methods have some disadvantages such as expensive instruments and extra pure solvents (i.e. HPLC). On the other hand, the simultaneous determination of three compounds with overlapped spectra is not possible using conventional spectrophotometric methods. So, developing alternative analytical techniques is very important for pharmaceutical samples because of the demand for simple, cheap and fast analytical methods.

Multivariate calibration methods are receiving considerable attention as quantitative analysis techniques. Recently, the PLS method has been applied for analysis of pharmaceutical and biomedical samples containing two or more components yielding overlapping spectra /4-14/.

In this study, we present a simple spectrophotometric method for simultaneous determination of DEX, PSE and TRP in Actidem syrup pharmaceutical formulations using PLS regression of PLS-2 formalism. In order to appraise the results obtained by PLS-2, a derivative spectrophotometric method was used and the results of two methods were compared.

\section{EXPERIMENTAL}

\section{Materials}

The DEX was supplied from Ilsan lltaş Drug Industry (Istanbul, Turkey), PSE was supplied from Plantafarma Drug Industry (Istanbul, Turkey), TRP and Actidem $^{\circledR}$ syrup were obtained from Glaxo Smith Kline Drug Industry (Istanbul, Turkey) . Other chemicals were of analytical reagent grade, and redistilled water was used throughout the work. The absorbance measurements were performed with an Agilent 8453 UV-Vis Spectrophotometer, using $1.00 \mathrm{~cm}$ quartz cells. PLS-2 was applied with an in-house program written according to the algorithm given by Martens and Naes /15/.

Stock solutions of DEX $\left(1000 \mu \mathrm{g} \mathrm{mL}^{-1}\right)$, PSE $\left(3000 \mu \mathrm{gL}^{-1}\right)$ and TRP $\left(100 \mu \mathrm{g} \mathrm{mL}^{-1}\right)$ werc prepared by dissolving in water. To obtain standard solutions for preparation of calibration matrix, stock solutions were diluted 
with water to $10 \mathrm{ml}$ containing $1 \mathrm{~mL}$ of $1 \mathrm{M} \mathrm{H}_{2} \mathrm{SO}_{4}$.

\section{Calibration set for PLS-2}

For preparation of calibration set, 27 proposed sample mixtures from a full-factorial three-level design for the three analytes were used $/ 16 /$. The selected levels were $60,80,100 \mu \mathrm{g} \mathrm{mL}^{-1}$ for DEX, $180,240,300 \mu \mathrm{g} \mathrm{mL}^{-1}$ for PSE and $8,10,12 \mu \mathrm{g} \mathrm{mL}^{-1}$ for TRP in this design (Table 1). The absorbances were recorded between 230 and $320 \mathrm{~nm}$ every $5 \mathrm{~nm}$.

Table 1

Composition of the calibration matrix for DEX, PSE and TRP ( $\left.\mu \mathrm{g} \mathrm{mL}^{-1}\right)$

\begin{tabular}{cccc}
\hline Standards & DEX & PSE & TRP \\
\hline 1 & 60 & 180 & 8 \\
2 & 60 & 240 & 8 \\
3 & 60 & 300 & 8 \\
4 & 80 & 180 & 8 \\
5 & 80 & 240 & 8 \\
6 & 80 & 300 & 8 \\
7 & 100 & 180 & 8 \\
8 & 100 & 240 & 8 \\
9 & 100 & 300 & 8 \\
10 & 60 & 180 & 10 \\
11 & 60 & 240 & 10 \\
12 & 60 & 300 & 10 \\
13 & 80 & 180 & 10 \\
14 & 80 & 240 & 10 \\
15 & 80 & 300 & 10 \\
16 & 100 & 180 & 10 \\
17 & 100 & 240 & 10 \\
18 & 100 & 300 & 10 \\
19 & 60 & 180 & 12 \\
20 & 60 & 240 & 12 \\
21 & 60 & 300 & 12 \\
22 & 80 & 180 & 12 \\
23 & 80 & 240 & 12 \\
\hline
\end{tabular}




\begin{tabular}{cccc}
\hline 24 & 80 & 300 & 12 \\
25 & 100 & 180 & 12 \\
26 & 100 & 240 & 12 \\
27 & 100 & 300 & 12 \\
\hline
\end{tabular}

\section{Validation set}

The validation set was prepared with three different levels of DEX, PSE and TRP, also a single level of excipients (100\%). Three groups of all samples were prepared and analysed three times a day for four consecutive weeks. This procedure allowed us to assess intra- and inter-assay accuracy and precision.

\section{Commercial sample preparation}

In analyzing the active components of Actidem syrup /1/, an accurately weighed amount of $10 \mathrm{~mL}$ of syrup to a $100 \mathrm{ml}$ separating funnel containing $30 \mathrm{~mL}$ of water.The solution was made alkaline by the addition of $2 \mathrm{~mL}$ of 5 $\mathrm{M} \mathrm{NaOH}$ and then extracted with three $20 \mathrm{~mL}$ volumes of chloroform. The extracts were combined in a second separating funnel and then extracted with 20,15 and $10 \mathrm{~mL}$ of $0.1 \mathrm{M} \mathrm{H}_{2} \mathrm{SO}_{4}$. The acidic extracts were combined and diluted to $50 \mathrm{~mL}$ in a volumetric flask. A 2 volume of the acidic extract was transferred to a $10 \mathrm{~mL}$ volumetric flask containing $0.6 \mathrm{~mL}$ of $1 \mathrm{M} \mathrm{H}_{2} \mathrm{SO}_{4}$ and the contens of flask were diluted to $10 \mathrm{~mL}$ with water. The absorbances of this solution were recorded between 230 and $320 \mathrm{~nm}$.

\section{RESULTS AND DISCUSSION}

The absorption spectra of the DEX, PSE and TRP are presented in Figure 1. As can be seen, the spectra were obviously overlapped and these compounds cannot be determined in the presence of each other by conventional spectrophotometric techniques.

In the present work, DEX, PSE and TRP were analysed in syrup samples by using PLS calibration. The PLS calibration is done by the composition of both concentration and absorbance matrix into latent variables, $A=\mathrm{TP}^{\prime}+\mathrm{E}$ and $C=\mathrm{UQ}^{\prime}+\mathrm{F}$. The PLS calculations also give an auxiliary matrix $W$ (PLS 
weights) which expresses the correlation between $U$ and $A$ and use to calculate T. The vector $b$ is given as $b=W\left(\mathrm{P}^{\prime} W\right)^{-1} Q$.

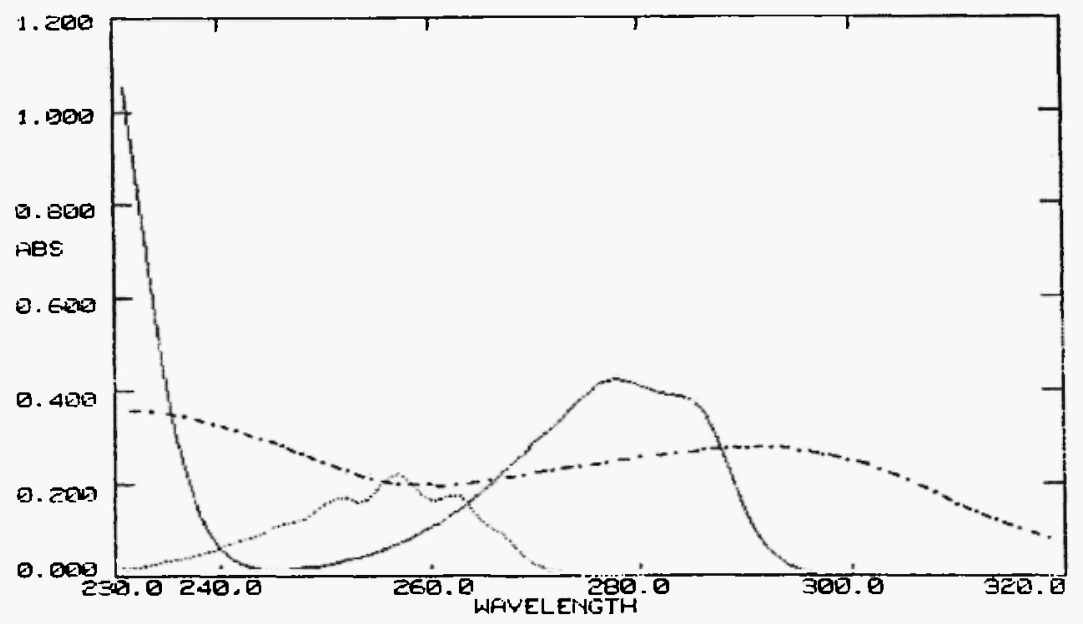

Fig. 1: Spectra of DEX (-) $80 \mu \mathrm{g} \mathrm{mL}^{-1}$, PSE (..) $240 \mu \mathrm{g} \mathrm{mL}^{-1}$ and TRP(-•-) $10 \mu \mathrm{g} \mathrm{mL}^{-1}$ in $0.1 \mathrm{M} \mathrm{H}_{2} \mathrm{SO}_{4}$

According to the PLS-2 algorithm, equations for three drugs were found as follows:

$$
\begin{aligned}
\mathrm{C}_{\mathrm{DEX}}= & 14.0060+8.23 \mathrm{~A}_{1}+10.10 \mathrm{~A}_{2}+14.34 \mathrm{~A}_{3}+20.46 \mathrm{~A}_{4}+23.50 \mathrm{~A}_{5}+ \\
& 20.93 \mathrm{~A}_{6}+15.59 \mathrm{~A}_{7}+5.48 \mathrm{~A}_{8}+3.24 \mathrm{~A}_{9}+3.16 \mathrm{~A}_{10}+2.84 \mathrm{~A}_{11}+ \\
& 1.72 \mathrm{~A}_{12}+1.14 \mathrm{~A}_{13}+0.96 \mathrm{~A}_{14}+0.79 \mathrm{~A}_{15}+1.09 \mathrm{~A}_{16}+0.67 \mathrm{~A}_{17} \\
\mathrm{C}_{\mathrm{PSE}}= & 62.1346+22.19 \mathrm{~A}_{1}+27.22 \mathrm{~A}_{2}+30.66 \mathrm{~A}_{3}+55.15 \mathrm{~A}_{4}+63.34 \mathrm{~A}_{5}+ \\
& 56.41 \mathrm{~A}_{6}+42.02 \mathrm{~A}_{7}+14.78 \mathrm{~A}_{8}+8.73 \mathrm{~A}_{9}+8.51 \mathrm{~A}_{10}+7.65 \mathrm{~A}_{11}+ \\
& 4.63 \mathrm{~A}_{12}+3.08 \mathrm{~A}_{13}+2.59 \mathrm{~A}_{14}+2.13 \mathrm{~A}_{15}+2.94 \mathrm{~A}_{16}+1.79 \mathrm{~A}_{17} \\
\mathrm{C}_{\mathrm{TRP}}= & -0.3093+1.29 \mathrm{~A}_{1}+1.58 \mathrm{~A}_{2}+2.24 \mathrm{~A}_{3}+3.20 \mathrm{~A}_{4}+3.67 \mathrm{~A}_{5}+3.27 \mathrm{~A}_{6}+ \\
& 2.44 \mathrm{~A}_{7}+0.86 \mathrm{~A}_{8}+0.51 \mathrm{~A}_{9}+0.49 \mathrm{~A}_{10}+0.44 \mathrm{~A}_{11}+0.27 \mathrm{~A}_{12}+0.18 \mathrm{~A}_{13}+ \\
& 0.15 \mathrm{~A}_{14}+0.12 \mathrm{~A}_{15}+0.17 \mathrm{~A}_{16}+0.10 \mathrm{~A}_{17}
\end{aligned}
$$

where $C_{D E X}, C_{P S E}$ and $C_{T R P}$ are the concentrations of DEX, PSE and TRP, $A_{1}$, $A_{2} \ldots . . . A_{25}$ are the absorbance values measured at 17 points between 230 and $320 \mathrm{~nm}$ for samples. These absorbance values were replaced in the above equation and the amount of each drugs in samples was computed. 


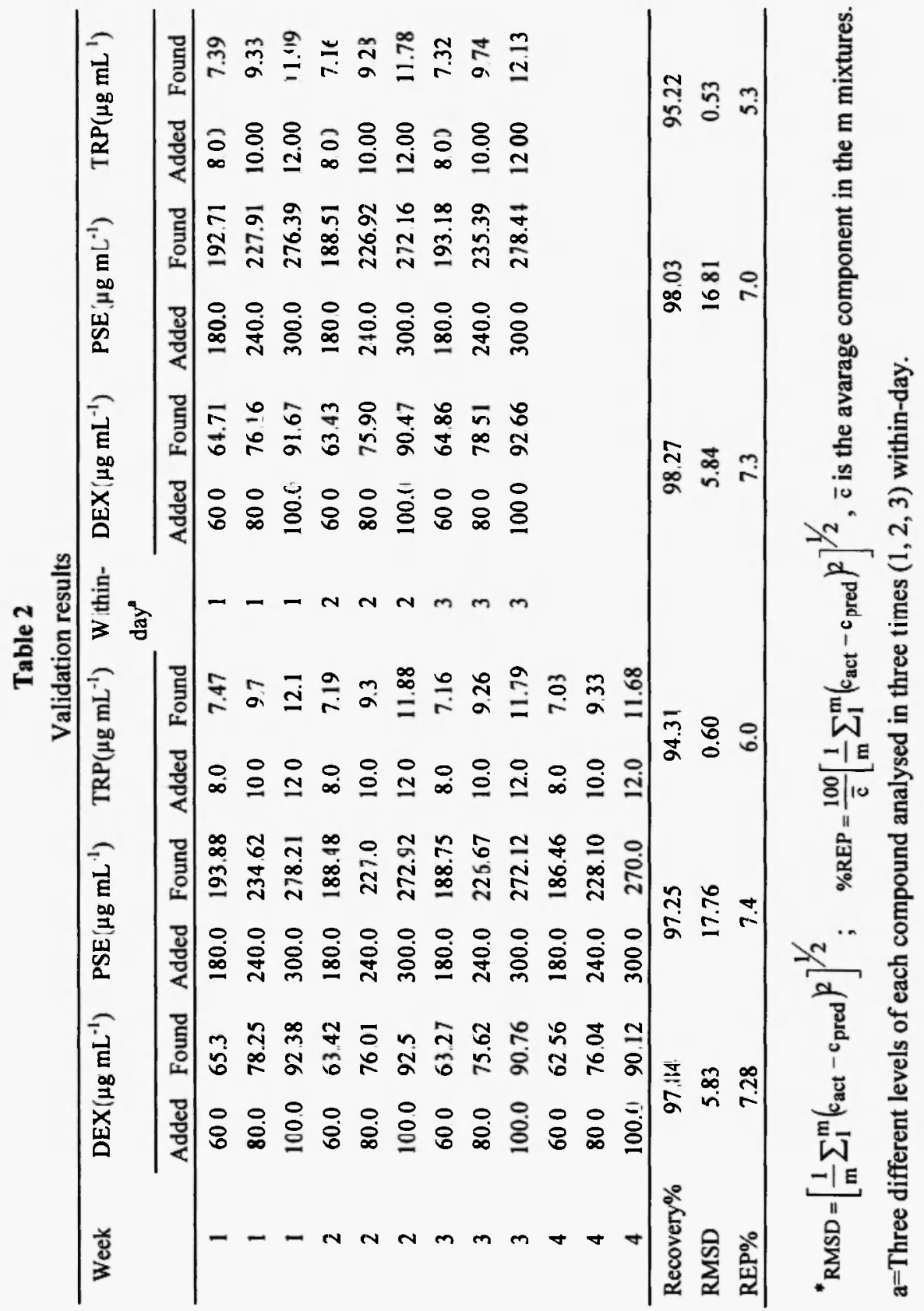




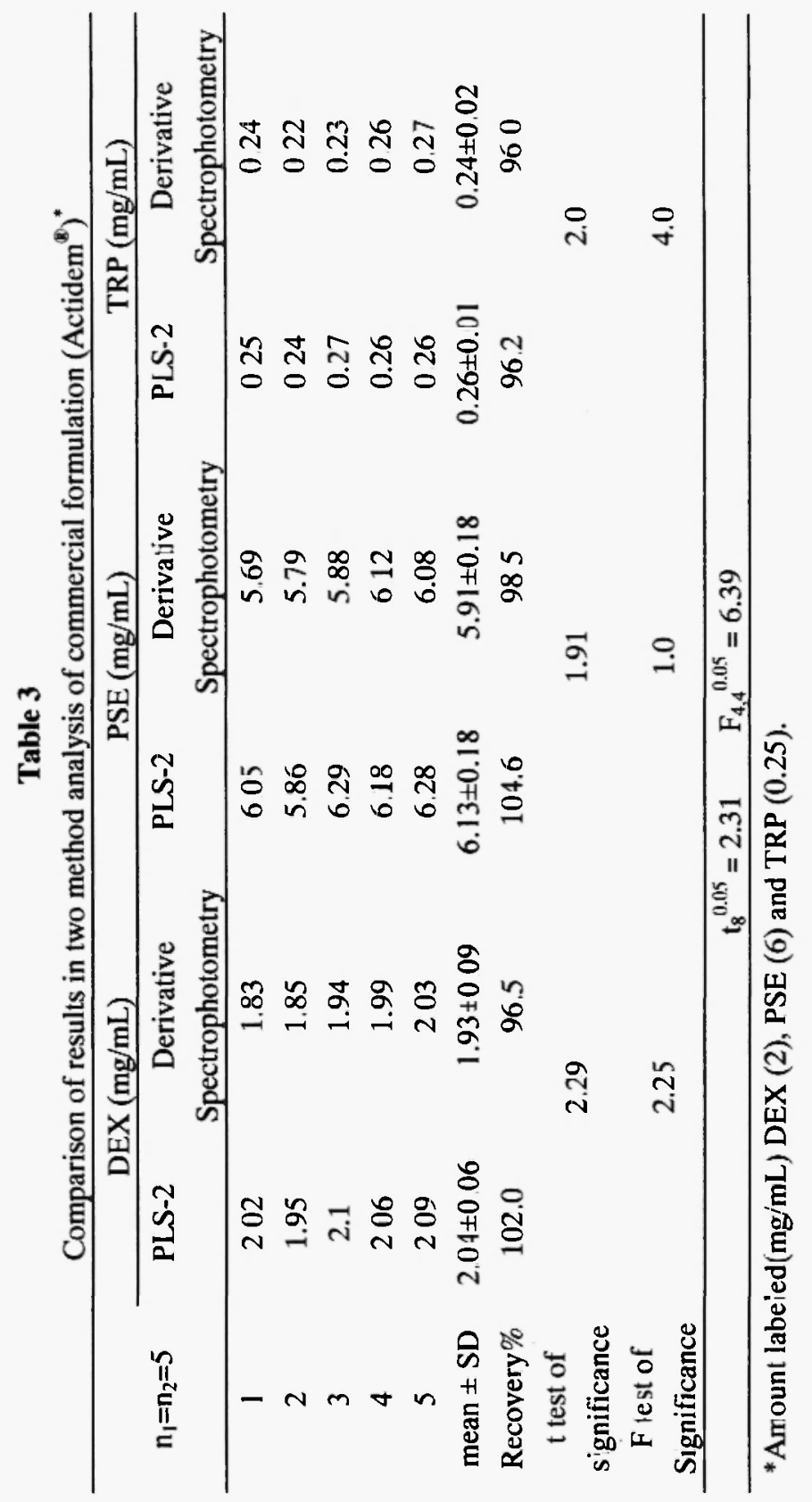


In order to test inter- and intra-assay accuracy and precision of the proposed method, placebo samples including the different concentrations of DEX, PSE and TRP carried out in four consecutive weeks and three times a day (Table 2). As regards the results provided by PLS-2 on the validation set, good recoveries were obtained for DEX, PSE and TRP (Relative error of prediction (REP\%) values not exceeded $15 \%$ ).

The PLS-2 method proposed in this study was compared with the derivative spectrophotometric method. In this method, PSE was determined from the second derivative peak to peak method at $257-260 \mathrm{~nm}$ and, DEX and TRP were determined from the first derivative zero-crossing method at 291 and $303 \mathrm{~nm}$, respectively /17,18/. All solutions were prepared as in PLS2 method. The assay results obtained by both methods were statistically compared at the 5\% level. As shown in Table 3 there were no significant differences between the mean values and precisions of the two methods and the recoveries can be considered as reasonably good in view of the usual limits of $90-110 \%$ established by regulatory agencies $/ 19,20 /$.

\section{CONCLUSION}

PLS-2 calibration was employed to analyse the ternary mixtures of DEX, PSE and TRP in the syrup samples. The results obtained by PLS-2 were compared with the derivative spectrophotometric method. This rapid, easy and cheap method can be proposed as a viable alternative to the routine analysis methods.

\section{REFERENCES}

1. A. G. Davidson and M. M. Mkoji, J. Pharm. Biomed. Anal., 6, 449 (1988).

2. R. Jones, M. J. Orchard and K. Hall, J. Pharm. Biomed. Anal., 3, 335 (1985).

3. D. D. Orsi, L. Gagliardi, A. Bolasko and D. Torelli, Chromatographia, 43, 496 (1996).

4. P. Geladi and B. Kowalski, Anal. Chim. Acta, 185,19 (1986).

5. M. Otto and W. Wegscheider, Anal. Chem., 57, 63 (1985). 
6. D. Haaland and E. Thomas, Anal. Chem., 60, 1193 (1988).

7. A. Bozdogan, G. Kunt and A. M. Acar, Anal. Letters 25, 2051 (1992).

8. A. Bozdogan, A. M. Acar and G. Kunt, Talanta 39, 977 (1992).

9. Ö. Aksu, A. Bozdogan and G. Kunt, Anal. Letters 31(5), 859 (1998).

10. M. S. Collado, V. E. Mantovani, H. C. Goicoechea and A. C. Olivieri, Talanta 52, 909 (2000).

11. G. Ragno, F.Aiello, A. Garofalo, G. Ioele and M. S. Sinicropi, Il Farmaco 58, 909 (2003).

12. Z. Rezaei, B. Hemmateenejad, S. Khabnadideh and M. Gorgin, Talanta 65, 21(2005).

13. E. Dinç, A. Ozdemir, and D. Baleanu, J. Pharm. Biomed. Anal. 37, 569 (2005).

14. Ö. Aksu, A. Bozdogan and G. Kunt, Anal.Letters 39(4), 751 ( 2006).

15. H. Martens and T. Naes., Multivariate Calibration, John Wiley: Chichester 1989.

16. D. C. Montgomery, Design and Analysis of Experiments, John Wiley: New York 1997.

17. J. L. Murtha, T. N Julian and G. Radebaugh, J. Pharm. Sci., 77, 715 (1988).

18. E. Dinç and F. Onur, STP Pharma Sciences 8(3), 203 (1998).

19. British Pharmacopoeia, H.M. Stationary Office: London, 1998.

20. J. M. Gren, Anal. Chem., 68, 305 (1996). 
